\title{
Preparation and Evaluation of Fast Dissolving Buccal Thin Films of Bufotenin
}

\author{
Venkateswarlu $\mathbf{K}^{*}$
}

Department of Pharmaceutics, JNTUA Oil Technological and Pharmaceutical Research Institute, Jawaharlal Nehru Technological University Anantapur, Ananthapuramu, India

*Corresponding author: Venkateswarlu K, Department of Pharmaceutics, JNTUA Oil Technological and Pharmaceutical Research Institute Jawaharlal Nehru Technological University Anantapur, Ananthapuramu-515001, Andhra Pradesh, India, Tel: +91-9441701016; E-mail: k.v.reddy9441701016@gmail.com

Received date: Oct 26, 2016; Accepted date: Nov 28, 2016; Published date: Dec 5, 2016

Copyright: (C) 2016 Venkateswarlu K. This is an open-access article distributed under the terms of the Creative Commons Attribution License, which permits unrestricted use, distribution, and reproduction in any medium, provided the original author and source are credited.

Citation: Venkateswarlu K. Preparationand Evaluation of Fast Dissolving Buccal Thin Films of Bufotenin. J In Silico In Vitro Pharmacol. 2016, 2:4

\section{Abstract}

The present investigation was undertaken with the objective of formulating Bufotenin for rapid dissolution of drug and absorption which may produce the rapid onset of action and also to improve the bioavailability of the drug. The fast dissolving strips were prepared by solvent casting method with the selection of HPMC E5, E15, K15, and Microcrystalline Cellulose (MCC), Polyvinyl Alcohol (PVA) as polymers and glycerol as plasticizer. Prepared films were carried out for in vitro evaluation tests such as film thickness, folding endurance, and content uniformity, estimation of moisture content, tensile strength, elongation, disintegration studies and dissolution studies. As per the official limits, film has to release the maximum amount of drug within a minute and it was satisfied by the formulations F1, F4, F7 and F8. It could be concluded from the results that the fast dissolving oral thin film can be a potential dosage form for pediatric and geriatric patients showing effective and faster drug release.

Keywords: Buccal delivery; Bufotenin; Dissolution studies; Fast dissolving films; Thin films

\section{Introduction}

Oral route is the most preferred route for the delivery of the drugs till the date due to ease of ingestion, pain avoidance and versatility (to accommodate various types of drug candidates). Also, solid oral delivery systems do not require sterile conditions and are, therefore, less expensive to manufacture, but oral drug delivery systems still need some advancements to be made because of their drawbacks related to particular class of patients which includes geriatric, paediatric and dysphagic patients associated with many medical conditions as they have difficulty in swallowing or chewing solid dosage forms [1-2]. Many paediatric and geriatric patients are unwilling to take solid preparations due to fear of chocking because of tablet appearance and patients experienced difficulty in swallowing tablets. Even fast dissolving tablets there are a fear of choking due to its tablet type appearance. For the last two decades, there had been an enhanced demand for patient-compliant dosage forms [3-4]. Research and development in the oral drug delivery segment had led to transition of dosage form from simple conventional tablets/ capsules to modified release tablets/capsules to Oral Disintegrating Tablet (ODT) to wafer to the recent development of oral dissolving film, "a thin film that is prepared using hydrophilic polymers that rapidly dissolves on the tongue or buccal cavity" [5].

Fast Dissolving Oral Films (FDOFs) are the most advanced form of oral solid dosage form due to more flexibility and comfort. It improves the efficacy of APIs by dissolving within minute in oral cavity after the contact with saliva without chewing and no need of water for administration. It gives quick absorption and instant bioavailability of drugs due to high blood flow and permeability of oral mucosa is 4-1000 times greater than that of skin. FDOFs are useful in patients such as paediatric, geriatric, bedridden, emetic patients, diarrhoea, sudden episode of allergic attacks, or coughing for these who have an active life style. It is also useful whether local action desired such as local anaesthetic for toothaches, oral ulcers, cold sores or teething [6].

Thin film drug delivery uses a dissolving film or oral drug strip to administer drugs via absorption in the mouth. The film is prepared using hydrophilic polymers that rapidly dissolves on the tongue or buccal cavity, delivering the drug to the systemic circulation via dissolution when contact with liquid is made. Thin film drug delivery has emerged as an advanced alternative to the traditional tablets, capsules [7]. Bufotenin is produced from a toad is a psychoactive compound and soluble in water. Bufotenin (tryptamine related to the neurotransmitter serotonin) is used in the brain disorders and acts by binding to the GABAA receptors at the same location as benzodiazepines [8]. The aim of present study was to prepare the fast dissolving thin films using the hydrophilic polymers. 


\section{Materials and Methods}

\section{Materials}

Bufotenin was purchased from EMCO industries, India. HPMC E5, HPMC E15 and HPMC K15 were procured from Dow Chemicals, USA. Remaining chemicals used were of analytical grade.

\section{Preparation of oral thin films}

Accurately weighed quantities of polymers (Table 1) were dissolved in distilled water, heated and made bubble free of the solution. To this plasticizer, glycerol and mannitol was added and mixed thoroughly followed by addition of drug and complete dissolution. The clear solution is now poured into cleaned specially designed glass molds. It was dried in hot air oven if necessary after $24 \mathrm{~h}$ of controlled evaporation at room temperature. The cast polymer films with different formulations were then peeled off covered with aluminum foils and stored in a desiccator until further study.

Table 1: Preparation of oral thin films.

\begin{tabular}{|c|c|c|c|c|c|c|c|c|}
\hline Ingredients & F1 & F2 & F3 & F4 & F5 & F6 & F7 & F8 \\
\hline Drug (mg) & 8 & 8 & 8 & 8 & 8 & 8 & 8 & 8 \\
\hline HPMC E15 (mg) & 10 & 20 & - & 10 & 15 & - & - & - \\
\hline $\mathrm{MCC}(\mathrm{mg})$ & 10 & 10 & - & - & - & - & - & - \\
\hline $\begin{array}{l}\text { Pregelatinsed Starch } \\
(\mathrm{mg})\end{array}$ & - & - & 10 & - & - & - & - & - \\
\hline HPMC K15 (mg) & - & - & 10 & - & - & - & - & - \\
\hline PVA (mg) & - & - & - & 10 & 15 & - & - & - \\
\hline HPMC E5 (mg) & - & - & - & - & - & 200 & 400 & 600 \\
\hline Glycerol (mg) & 70 & 70 & 70 & 70 & 70 & 70 & 70 & 70 \\
\hline Mannitol (mg) & 100 & 100 & 100 & 100 & 100 & 100 & 100 & 100 \\
\hline Vanilla (mg) & 5 & 5 & 5 & 5 & 5 & 5 & 5 & 5 \\
\hline Water (ml) & q.s & q.s & q.s & q.s & q.s & q.s & q.s & q.s \\
\hline Total weight (mg) & 203 & 213 & 203 & 203 & 213 & 383 & 583 & 783 \\
\hline
\end{tabular}

\section{Evaluation of oral thin films}

The prepared thin films were evaluated for the properties such as Percentage elongation, tensile strength, Folding endurance, thickness, moisture content, moisture uptake, Drug content according to the methods reported previously [9-10].

\section{Disintegration test}

Disintegration refers to the physical process by which a film dissolves into a solution. Disintegration times were measured in vitro for six samples by the standard United States Pharmacopeia (USP) disintegration method in artificial saliva [11] at $37^{\circ} \mathrm{C}$ using the disintegration apparatus (Electrolab, ED-2L, India). The time required for full disintegration was recorded for each film [12].

\section{Dissolution test}

In vitro dissolution test was carried out according to the USP II paddle dissolution apparatus (Lab India, India). The test solution was $900 \mathrm{~mL}$ of $\mathrm{pH} 6.8$ phosphate buffer at $37 \pm 0.5^{\circ} \mathrm{C}$ and the rotation rate of $75 \mathrm{rpm} .5 \mathrm{~mL}$ sample of the dissolution medium was withdrawn at regular time intervals. After each withdrawal, an equal volume of dissolution medium was replaced. The absorbance was measured using UV-Visible spectrophotometer (Lab India, India) at $295 \mathrm{~nm}$ and the percent drug released was calculated [12-13].

\section{Stability studies}

Stability studies on selected formulations were conducted according to International Conference on Harmonization (ICH) guidelines. Stability studies were carried out for the best film F7, stored in an aluminum package in a chamber (Electrolab, India) controlled at $40^{\circ} \mathrm{C}$ and $75 \% \mathrm{RH}$ for 3 months. The films were subjected to the evaluation parameters [14].

\section{Results and Discussion}

Fast dissolving oral thin films of Bufotenin were prepared by solvent casting method using hydrophilic polymers. Totally 8 formulations were designed and evaluated for optimization. Plasticizer is an important ingredient in fast dissolving films, 
which improves the flexibility and reduces the brittleness of the films. Specifically, the plasticizer improves the film forming property by reducing the glass transition temperature of the polymers [15]. From the earlier studies, glycerol was selected as a plasticizer and Vaishali et al reported that the increase in glycerol concentration from $60 \mathrm{mg}$ to $100 \mathrm{mg}$ showed decrease in disintegration time [16]. Hence, in the present study, glycerol concentration was kept constant in all the formulations. The difference in the disintegration time might be due to the presence of other ingredients like polymers etc. As per criteria of oral thin films, drug has to be released from the film within $60 \mathrm{~s}$ and it was satisfied by the formulations like F1, F4, F7 and F8. Hence these formulations were selected for further studies and optimized. Remaining formulations were omitted for further studies because they did not meet the criteria of oral thin films according to which disintegration should take place in less than a minute (Table 2).

Table 2: Disintegration times of different batches of prepared oral thin films.

\begin{tabular}{|l|l|}
\hline Formulation & Disintegration time (s) \\
\hline F1 & 49 \\
\hline F2 & 90 \\
\hline F3 & No film \\
\hline F4 & 57 \\
\hline F5 & 85 \\
\hline F6 & No film \\
\hline F7 & 23 \\
\hline F8 & 47 \\
\hline
\end{tabular}

\section{Physical parameters}

The tensile strength of each film was determined and the data obtained is given in Table 3. The data reveal that tensile strength varies from $1.8-2.2 \mathrm{~N} / \mathrm{m}^{2}$. Addition of polymers and increase in polymer weight/ratio shows a significant increase in the tensile strength. The data indicates that as the concentration of polymer increases thickness increases. Thickness is directly proportional to tensile strength. In other words as thickness increases tensile strength also increases. Low moisture content ensures stability and prevents the formation of dried and brittle films. The moisture uptake of the formulations indicates that in high humid environment, the patches take up very little moisture (1-2\%). This may favour the stability as well as compatibility with high humid conditions of the formulations. The drug content of the prepared films were in the range of $92-98 \%$.

Table 3: Physical properties of the prepared oral thin films.

\begin{tabular}{|c|c|c|c|c|c|c|}
\hline Formulation & $\begin{array}{l}\text { Thickness of } \\
\text { patch }(\mu \mathrm{m})\end{array}$ & Tensile strength $\left(\mathrm{N} / \mathrm{m}^{2}\right)$ & Elongation (\%) & $\begin{array}{l}\text { Moisture content } \\
(\%)\end{array}$ & $\begin{array}{l}\text { Moisture uptake } \\
(\%)\end{array}$ & Drug content (\%) \\
\hline $\mathrm{F} 1$ & $39 \pm 0.01$ & $1.689 \pm 0.18$ & $9.3 \pm 0.65$ & $2.89 \pm 0.05$ & $2.85 \pm 0.05$ & $92.6 \pm 1.1$ \\
\hline $\mathrm{F} 4$ & $43 \pm 0.02$ & $1.865 \pm 0.23$ & $10.1 \pm 0.59$ & $3.01 \pm 0.11$ & $3.12 \pm 0.09$ & $93.8 \pm 2.1$ \\
\hline $\mathrm{F} 7$ & $56 \pm 0.01$ & $1.72 \pm 0.78$ & $10.3 \pm 0.62$ & $3.23 \pm 0.25$ & $3.23 \pm 0.35$ & $91.6 \pm 1.12$ \\
\hline F8 & $67 \pm 0.03$ & $2.13 \pm 0.65$ & $11.2 \pm 0.12$ & $3.12 \pm 0.68$ & $3.31 \pm 0.76$ & $97.8 \pm 1.74$ \\
\hline
\end{tabular}

\section{In vitro dissolution studies}

From the in vitro drug release studies, F7 showed highest drug release compared to all other formulations. Amongst all the polymers, HPMC E5 showed fast dissolving of drug. Therefore F7 batch was selected for further stability studies (Table 4).

\section{Stability studies}

From the stability studies, it was confirmed that the formulation $\mathrm{F} 7$ was stable for 90 days and not observed much variations in the properties like elongation, tensile strength, thickness, moisture content, moisture uptake, drug content, and dissolution data. Hence, there is a lot of scope for future in vivo studies (Tables 5 and 6). 
Table 4: In vitro dissolution data of Bufotenin.

\begin{tabular}{|l|l|l|l|l|}
\hline \multirow{2}{*}{ Time (min) } & \multicolumn{2}{|l|}{$\%$ Cumulative Drug Release } & F7 & F8 \\
\cline { 2 - 5 } & F1 & F4 & 0 & 0 \\
\hline 0 & 0 & $63.8 \pm 0.16$ & $65.2 \pm 0.83$ & $57.24 \pm 0.83$ \\
\hline 2 & $59.8 \pm 0.23$ & $80.92 \pm 0.89$ & $82.5 \pm 0.45$ & $77.82 \pm 0.46$ \\
\hline 4 & $79.2 \pm 0.45$ & $92.23 \pm 0.78$ & $97.2 \pm 0.27$ & $85.4 \pm 0.96$ \\
\hline 5 & $87.2 \pm 0.56$ & $94.7 \pm 1.45$ & $98.9 \pm 0.63$ & $93.2 \pm 0.81$ \\
\hline 7 & $95.2 \pm 0.41$ & & \\
\hline
\end{tabular}

Table 5: Physical properties of the prepared oral thin film of F7.

\begin{tabular}{|c|c|c|c|c|c|c|}
\hline $\begin{array}{l}\text { Time } \\
\text { (days) }\end{array}$ & Elongation (\%) & Tensile strength $\left(\mathrm{N} / \mathrm{m}^{2}\right)$ & $\begin{array}{l}\text { Thickness } \\
\text { patch }(\mu \mathrm{m})\end{array}$ & $\begin{array}{l}\text { Moisture content } \\
(\%)\end{array}$ & $\begin{array}{l}\text { Moisture uptake } \\
(\%)\end{array}$ & Drug content (\%) \\
\hline 0 & $11.2 \pm 0.11$ & $1.79 \pm 0.25$ & $48 \pm 0.01$ & $3.01 \pm 0.09$ & $3.13 \pm 0.07$ & $92.5 \pm 0.9$ \\
\hline 30 & $11.2 \pm 0.21$ & $1.783 \pm 0.33$ & $48 \pm 0.02$ & $3.01 \pm 0.22$ & $3.13 \pm 0.09$ & $91.8 \pm 1.2$ \\
\hline 60 & $10.9 \pm 0.78$ & $1.79 \pm 0.43$ & $49 \pm 0.01$ & $3.01 \pm 0.1$ & $3.13 \pm 0.05$ & $91.5 \pm 1.5$ \\
\hline 90 & $10.7 \pm 1.2$ & $1.778 \pm 0.56$ & $48 \pm 0.01$ & $3.01 \pm 0.13$ & $3.13 \pm 0.03$ & $92.1 \pm 1.3$ \\
\hline
\end{tabular}

Table 6: In vitro dissolution data of Bufotenin buccal thin films.

\begin{tabular}{|c|c|c|c|c|}
\hline \multirow{2}{*}{$\begin{array}{l}\text { Time } \\
\text { (min) }\end{array}$} & \multicolumn{4}{|c|}{$\%$ cumulative drug release } \\
\hline & 0 day & 30 days & 60 days & 90 days \\
\hline 0 & 0 & 0 & 0 & 0 \\
\hline 2 & $5.15 \pm 0.31$ & $64.92 \pm 0.97$ & $65.12 \pm 1.85$ & $65.30 \pm 1.35$ \\
\hline 4 & $81.20 \pm 1.54$ & $81.13 \pm 0.49$ & $81.25 \pm 0.93$ & $81.25 \pm 1.15$ \\
\hline 5 & $97.30 \pm 0.85$ & $96.20 \pm 0.68$ & $96.80 \pm 0.35$ & $97.20 \pm 0.84$ \\
\hline 7 & $98.70 \pm 0.47$ & $98.50 \pm 0.71$ & $98.40 \pm 0.38$ & $98.60 \pm 0.76$ \\
\hline
\end{tabular}

\section{Conclusion}

The oral thin films of Bufotenin were designed using different polymers by solvent casting method and evaluated in vitro. It could be concluded from the results that the polymer HPMC E5 showed highest drug release rate than other polymers and F7 showed highest drug release rate. Stability studies indicated $\mathrm{F} 7$ was stable for 90 days. Hence, there is a lot of scope for future in vivo studies.

\section{References}

1. Vijayabhaskar K, Venkateswarlu K, Thirumalesh Naik SB, Kiran Jyothi R, Nethra Vani G, et al. (2016) Preparation and in vitro Evaluation of Ranitidine Mucoadhesive Microspheres for Prolonged Gastric Retention. Br J Pharm Res 10: 1-12.

2. Venkateswarlu K, Thirumalesh Naik SB, Chandrasekhar KB (2016) Formulation and in vitro evaluation of orlistat orodispersible tablets for enhancement of dissolution rate. Int J Pharm Pharm Sci 8: 236-241.
3. Thirumalesh Naik SB, Venkateswarlu K, Chandrasekhar KB (2016) Formulation and in vitro evaluation of orodispersible tablets of olanzapine for the improvement of dissolution rate. J Chem Pharm Res 8: 177-181.

4. Thirumalesh Naik SB, Venkateswarlu K, Chandrasekhar KB (2016) Formulation and evaluation of Oxybutynin chloride extended release matrix tablets. Indo Am J Pharm Res 6: 4179-4184.

5. Naziya K, Raghavendra Rao NG, Mahipal Reddy B (2014) Formulation and evaluation of oral fast dissolving films of montelukast sodium. Int J Pharm Sci Res 5: 1780-1787.

6. Alka T, Kiran S, Nitesh SC, Ashu M, Umakant B (2012) Formulation and Evaluation of Fast Dissolving Oral Film of Dicyclomine as potential route of Buccal Delivery. Int J Drug Dev Res 4: 408-417.

7. Chamakura RP (1994) Bufotenine - A Hallucinogen in Ancient Snuff Powders of South America and a Drug of Abuse on the Streets of New York City. Forensic Sci Rev 6: 1-18.

8. Prasad N (2015) Detection of antidiabetic activity by crude paratoid gland secretions from common Indian toad (Bufomelano stictus). J Nat Sci Biol Med 6: 429-433. 
9. Semalty A, Mona S, Nautiyal U (2010) Formulation and evaluation of mucoadhesive buccal films of enalapril maleate. Indian J Pharm Sci 72: 571-575.

10. Nappinnai M, Chandanbala R, Balaijirajan R (2008) Formulation and evaluation of nitrendipine buccal films. Indian J Pharm Sci 70: 631-635.

11. David H, Jamie K, Tamas T, Joel R (2013) An in vitro analysis of disintegration times of different formulations of olanzapine orodispersible tablet: A preliminary report. Drugs R D 13: 281-288.

12. Nagendrakumar D, Keshavshetti GG, Pratibha M, Swati S, Harshanand S (2015) Formulation and evaluation of fast dissolving oral films of metoprolol sccinate. Int J Eng Appl Sci 6: 28-38.
13. Venkateswarlu K, Preethi JK, Chandrasekhar KB (2016) Formulation and in vitro evaluation of loperamide immediate release tablets by liquisolid technique. Adv Pharm Bull 6: 385-390.

14. Venkateswarlu K (2013) in vitro stability testing of syrup dosage form for Hepatitis. Am J Phytomed Ther 1: 491-497.

15. Upendra CG, Sunil SK, Yuvraj GJ, Praveen DC (2013) Investigation of different polymers, plasticizers and superdisintegrating agents alone and in combination for use in the formulation of fast dissolving oral films. Int J PharmTech Res 5: 1465-1472.

16. Vaishali YL, Kashmira B (2012) Formulation development and evaluation of fast dissolving film of telmisartan. Indian J Pharm Sci 74: 122-126. 